International Journal of Engineering \& Technology, $7(4.3)(2018) 135-139$
International Journal of Engineering \& Technology
SPC
Website: www.sciencepubco.com/index.php/IJET
Research paper

\title{
Driven Camshaft Power Mechanism of the Vehicle Diesel Engine Fuel Pump
}

\author{
Mykola Moroz $^{1}{ }^{*}$, Serhii Korol ${ }^{1}$, Serhii Chernenko ${ }^{1}$, Yurii Boiko ${ }^{1}$, Oleksii Vasylkovskyi ${ }^{2}$ \\ ${ }^{1}$ Kremenchuk Mykhailo Ostohradskyi National University \\ ${ }^{2}$ Central Ukrainian National Technical University \\ *Corresponding author E-mail: mykolai.moroz@gmail.com
}

\begin{abstract}
The article deals with the actual problem associated with poor-quality operation of vehicle engines with incomplete loading and operation at partial high-speed modes. It is shown that such engine operating modes make up the bulk of the time, especially when the vehicle operates in urban conditions. Poor engine performance in these modes results in decline in fuel economy and environmental performance. To improve the technical performance of diesel engines, a device is proposed that allows control the uneven rotation of camshaft of vehicle diesel fuel pump. The kinematic schemes of the angular velocity transducers for fuel pump camshaft power mechanism, the kinematic and power drive calculation method are developed.
\end{abstract}

Keywords: Camshaft, Diesel Engine, Fuel Pump, Kinematic Diagram, Partial Modes of Diesel Engine Operation.

\section{Introduction}

Modern automobile engines have a low workload while operating, especially in urban conditions. Small loads and idling modes [1] make up more than $50 \%$. At the same time, fuel costs increase and environmental indicators deteriorate. The problem of increasing operational economic and environmental indicators is relevant The researches of passenger traffic flow carried out in works $[2,3,4]$ confirm incomplete loading of the vehicle engine in a city mode operation. The operational fuel economy of a vehicle diesel engine is determined by the economy of the partial load modes conducted by the researches in $[5,6,7]$.

In work [8] the basic principles of organization of driven uneven rotation of vehicle four-cycle internal combustion engine camshaft are described. According to this method, it is also possible to organize driven uneven rotation of the camshaft of high pressure fuel pump, which allows improve the fuel injection characteristics at partial high-speed $[9,10,11,12]$ diesel engine operation. This can be achieved by stabilizing the linear speed of fuel pump plungers regardless of crankshaft rotational rate of the vehicle diesel engine. In the power transmission connecting the diesel engine crankshaft to the pump camshaft, it is consistently proposed to install two identical angular velocity transducers, which can be made in the form of Hooke's joints in this device. The advantages of this choice of transducers include the fact that, firstly, these joints refer to the traditional and well-studied elements of mechanical transmissions produced in series. Secondly, one turnover of Hooke's main shaft has not one (as for most other types of transducers), but two periods of the output shaft angular velocity, which facilitates the use of these transducers to drive camshafts with a large number of cams. Thirdly, as it turned out as a result of the kinematic analysis of the new drive, the law of angular velocity variation provided by Hooke's joint proved to be very successful for calculating the mechanism using two consecutively operating angular velocity transducers. And, finally, fourthly, when using these joints, the drive remains kinematically closed and provides the calculated law of camshaft angular velocity variation with the alternating nature of the transmitted torque.

However, this solution is applicable only to diesel engines with a uniform alternation of fuel flares in the cylinders. Besides, it has, as it was demonstrated by its detailed design, a significant drawback: the longitudinal dimension (length) of the new assembly exceeds the length of the automatic injection advancing clutch, in the place of which it should be installed, from 2.5 to 3 times. Therefore, the proposed device can be used only in those cases when the engine does not have a rigid restriction in the place of fuel pump installation. In particular, such a drive can be successfully used in the development of a motor bench with fuel variable injection rate. The bench equipped with these transducers and a device for manual adjustment of the degree of pump shaft rotation unevenness will make it possible to obtain experimental data on the dependence of the working process parameters on the fuel injection intensity for each characteristic engine operation mode, which in turn will improve the design of its fuel equipment. The mentioned above increase in drive size is due to the fact that Hooke's joint refers not to flat, but to spatial mechanisms. Therefore, in this paper, it is proposed to use a kinematic analogue of Hooke's joint as a transducer, which belongs to the class of plane cam-and-lever mechanisms.

\section{Related Work}

In order to control uneven rotation of fuel pump camshaft on diesel engine partial operating conditions, it is proposed to use a cam-and-lever transducer of shaft rotation angular speeds in this work. The principal kinematic diagram of cam-and-lever mechanism is shown in Fig. 1. 


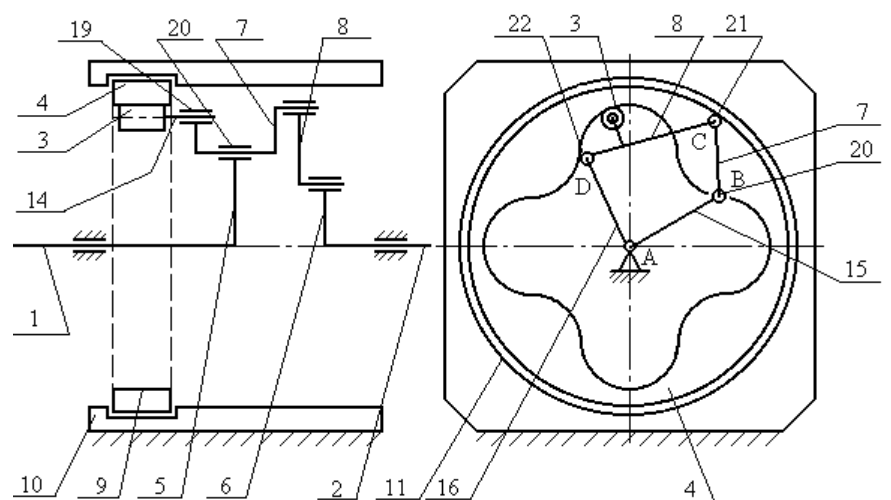

Fig. 1: Principal kinematic diagram of cam-and-lever mechanism.

Letters A, B, C, D denote the axes of the cylindrical joints connecting articulated chain joints. Point $\mathrm{A}$ is located on the common axis of the input transducer shaft 1 and output transducer shaft 2 . While roller 3 floating movement along the cam plate internal profile 4 the BAD angle changes between the driving 5 and the driven 6 cranks, as a result of which in some sections of the profile the driven crank overtakes the driving one, and on the other it lags behind. The $j$ instantaneous gear ratio for the $\omega_{2}, \omega_{1}$ angular velocities of the shafts 2 and 1 depends on the profile shape, so if the profile is repeated with a period $\mathrm{T}_{\mathrm{p}}=360^{\circ} / \mathrm{K}$, where $\mathrm{K}$ is an integer, then $\mathrm{j}$ transmission correlation variation law will have the same period. For the cam plate shown in Fig. $1, \mathrm{~T}_{\mathrm{p}}=90^{\circ}$. It should be noted that it was possible to obtain such a period using Hooke's joints only by means of additional, cylindrical gears rising before the new mount and lowering afterwards.

The scheme shown in Fig.1, does not disclose the mechanism of higher pair kinematic closure. Therefore, in the proposed mechanism, a kinematic closure scheme was developed, shown in Fig. 2.

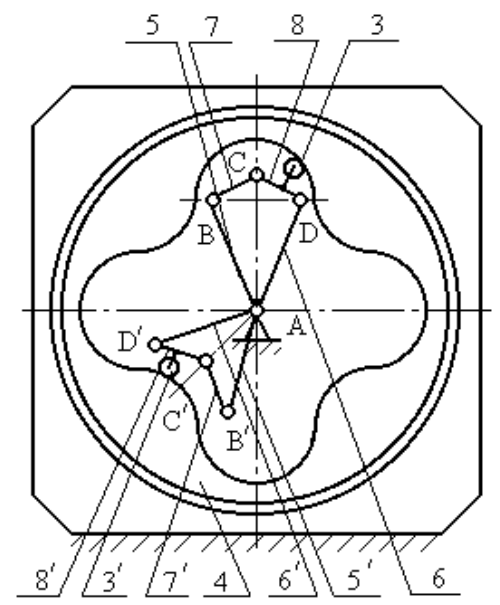

Fig. 2: Scheme of cam-and-lever mechanism kinematic closure.

To solve this problem, the angular velocity transducer is equipped with an additional cam-and-lever mechanism identical to the first one. Cranks 5,6,5',6 and connecting rods $7,8,7^{\prime}, 8^{\prime}$ of these mechanisms form convex $\mathrm{A}, \mathrm{B}, \mathrm{C}, \mathrm{D}$ and nonconvex $\mathrm{A}^{\prime}, \mathrm{B}^{\prime}, \mathrm{C}^{\prime}, \mathrm{D}^{\prime}$ tetragons in the plane of articulated chains with the same $\mathrm{BAD}$ and $\mathrm{B}^{\prime} \mathrm{A}^{\prime} \mathrm{D}^{\prime}$ angles between the driving and the driven cranks. The rollers 3 and $3^{\prime}$ of the first and second mechanisms contact with one working profile of the common cam plate 4 . The angle between the driving cranks 5 and $5^{\prime}$ (as well as the angle between the driven cranks 6 and $6^{\prime}$ ) of these mechanisms is a multiple of half the angle $T_{p}$ of the periodic repetition of the cam plate 4 profile (in Fig. 2 the angle $\mathrm{T}_{\mathrm{p}}$ is equal to $90^{\circ}$, and the angle between the driving (driven) cranks is $135^{\circ}$ ). With such device operation, rollers 3 and 3 move on the common profile of the cam plate, and the $\mathrm{ABCD}$ and $\mathrm{A}^{\prime} \mathrm{B}^{\prime} \mathrm{C}^{\prime} \mathrm{D}^{\prime}$ tetragons alternately become convex and nonconvex. In this mechanism, the articulated chain is convex (in Figure 2 it is the ABCD chain), roller 3, resting on the profile, prevents the angle between the driving and driven cranks from decreasing, while the roller of the other mechanism (in Figure 2 it is roller $3^{\prime}$ ), staying on the same profile, prevents the angle increase between the driving and the driven cranks. Since the driving cranks $5,5^{\prime}$ and the driven cranks $6,6^{\prime}$ are rigidly connected to each other, this arrangement ensures the continuous operation of the cam and roller profiles. In other respects, the device operation is similar to that described above.

In this device, cranks 5 and 6 approach each other when the $\mathrm{C}$ joint is removing from the BD straight line both towards the point A and to the side opposite to it. Therefore, in this case, the period $T_{2}$ of $\omega_{2}$ angular velocity change in the driven shaft 2 rotation (Figure 1) is only half of the $T_{p}$ angle of the periodic repetition of cam plate profile shape, and the angle between the cranks 5 and $5^{\prime}$ is a multiple of this half of the $T_{p}$ angle (that is, it is a multiple of the angle $\mathrm{T}_{2}$ ). In particular, this means that the cam plate profile with four projections, shown in Fig. 2, corresponds to the value of the angle $T_{2}=45^{\circ}$ and a transducer with such a cam plate should be used in the camshaft drive with 8-cams. In Fig. 3 the shapes of cam plates profiles used in the drive of 6,4 and 2 camshafts are shown.
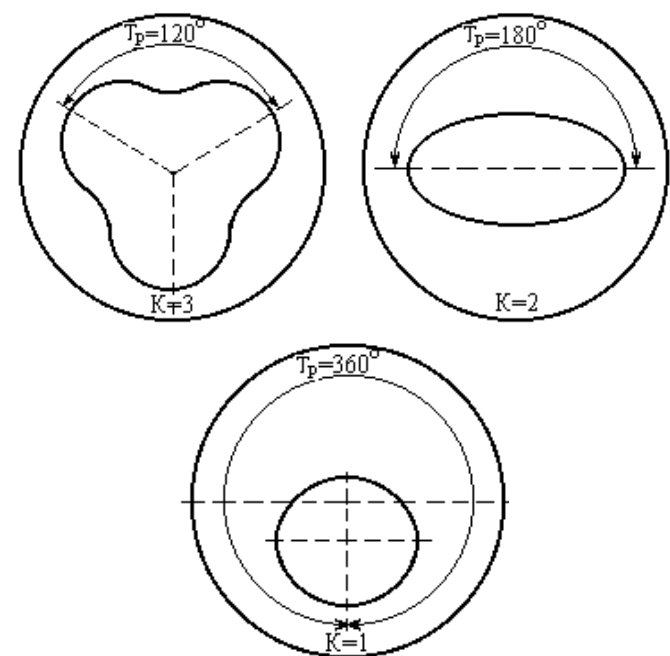

Fig. 3: Forms of cam plate internal profile for: a) six-plunger; b) fourplunger; c) two-plunger pumps.

Note that the group of engine cylinders, the fuel pump plunger which are driven by this camshaft, when using such a kinematic closure scheme must have a uniform alternation of fuel flares in the cylinders.

Let us carry out a kinematic calculation of a double cam-and-lever mechanism. In Fig. 4, a kinematic diagram of a double cam-andlever mechanism is shown, in which 13 and 25 rollers axes are inserted into socket 19 on the driving connector rods 17,30 of the transducer 45 . On the driven connector rods 18,31 of the transducer 46, the cylindrical holes 85 are arranged at equal distances from the geometric axis 8 of the cam plate 7. Cam plates 7 are made with internal profiles 9. The articulated chains are assembled so that the driven cranks are rotated in correlation to the driving cranks in the rotation direction. The cam plates 7 are inserted into the sockets 11 with the opposite orientation of the profiles 9 .

This set of characteristics ensures the fulfillment of the condition of the $j_{45}(\varphi), j_{46}(\varphi)$ gear ratio laws identity. In addition, in the operation of such device, the maximum operating torque corresponding to the maximum force of the fuel pressure on the plunger is transmitted through the articulated chains in the form of compressive rather than a tensile force (the driving joints "push" the driven ones). 


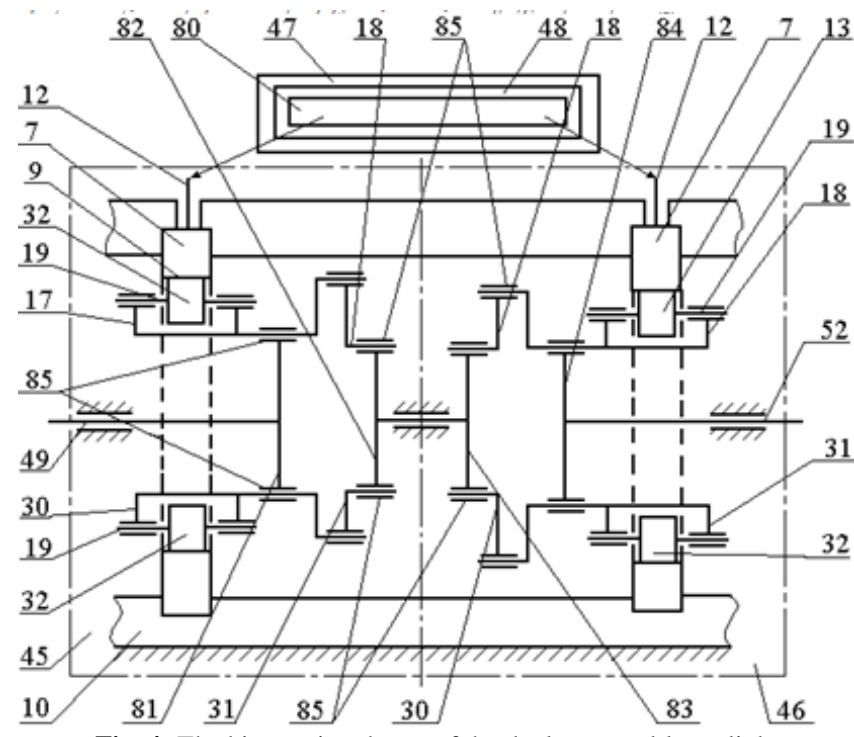

Fig. 4: The kinematic scheme of the dual cam-and-lever link.

In this case, only the chains that at this moment have the configuration of a convex tetragon (in Figure 2 it is the $A B C D$ chain, but not the $\mathrm{AB}^{\prime} \mathrm{C}^{\prime} \mathrm{D}^{\prime}$ chain) perceive this load. This reduces the reactions magnitude in the mechanism joints and the maximum value of contact tension is on profile 9 of cam plate 7 , which increases its reliability and durability. The block diagram of the drive using the cam-and-lever mechanisms of the described construction is shown in Fig. 5. Two identical angular velocity converters 11 and 12 are installed in series between the engine distributor shaft 9 and the fuel pump shaft 10, the scheme of which was shown in Fig. 1 and 2. In this device, the degree of the pump shaft rotation unevenness is regulated by an automatic regulator 13 that turns the cam plates of the transducers 11 and 12 to certain angles $\delta_{1}$ and $\delta_{2}$ and fixes them in each new position by means of special self-locking fasteners 14, 15. Rotation of cams plates changes the transfer functions phase.

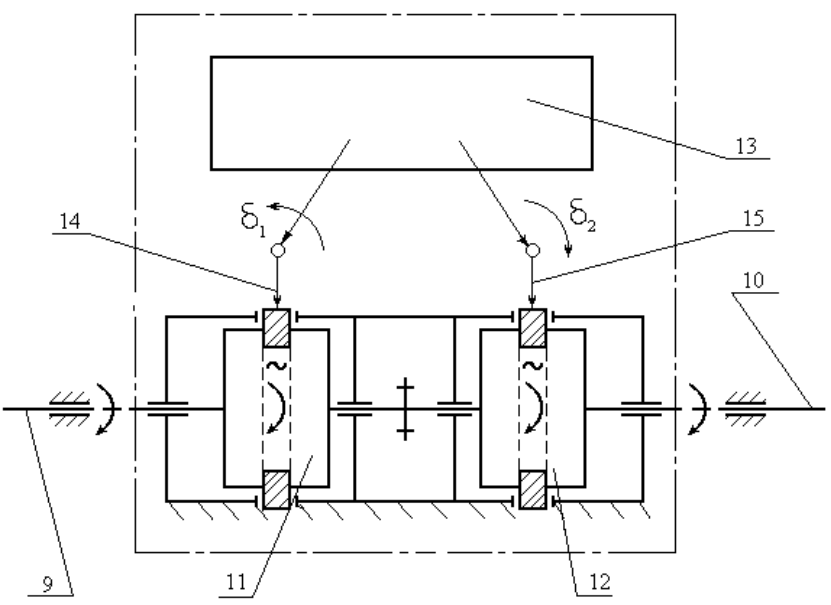

Fig. 5: The enlarged structural diagram of the mechanism which is used for its kinematic calculation.

The law of variation of gear ratio $\mathrm{j}$ between drive shaft 9 and fuel pump shaft 10 is determined by the following dependencies

$$
j=1+2 R_{0}^{2}+2 R_{0}\left(1+R_{0}^{2}\right)^{0.5} \sin \left[2 K\left(\varphi_{10}-\beta_{1}\right)\right]
$$

or

$$
j=\left[1+2 R_{0}^{2}+2 R_{0}\left(1+R_{0}^{2}\right)^{0.5} \sin \left[2 K\left(\varphi_{9}-\beta_{2}\right)\right]\right]^{-1}
$$

where $\mathrm{R}_{0}$ is a unevenness parameter,
$R_{0}=0.5\left(A_{0}^{-1}-A_{0}\right) \sin (K \delta)$,

$\delta$ is cam plates relative shift, $\delta=\delta_{2}-\delta_{1}$;

$\beta_{1}, \beta_{2}$ are sinusoid phases, $\beta_{1}=\beta-0.5 \Delta, \beta_{2}=-\beta-0.5 \Delta$,

$\left.\beta=(0,5 / K) \cdot \operatorname{arctg}\left[0.5\left(A_{0}+A_{0}^{-1}\right)\right] \cdot \operatorname{tg}(K \delta)-0.5 \delta\right]$,

$\Delta$ is cam plates one-sided shift, $\Delta=\delta_{1}+\delta_{2}$;

$\varphi_{9}, \varphi_{10}$ are current values of shaft rotation angles 9 и 10 .

$\mathrm{A}_{0}=\cos \alpha$.

The relative shift $\theta_{0}$ of shafts 9 and 10 , calculated at the moment of the maximum of the gear ratio $\mathrm{j}$, now, as it follows from formulas (1) to (4), is determined by the dependence

$\theta_{0}=\left[\operatorname{arctg}\left(0.5\left(A_{0}+A_{0}^{-1}\right) \operatorname{tg}(K \delta)\right)-K \delta\right] / K$

The function used in (6)

$f(\varphi)=\operatorname{arctg}(Z \cdot \operatorname{tg} \varphi)-\varphi$

on the $\varphi \in[0 ; \pi / 2]$ angles interval is non-negative (for $Z>1$ ), it equals to zero at its ends and takes a maximum value

$f_{\text {max }}=\operatorname{arctg}(Z-1) /(2 \sqrt{Z})$.

Analysis of the obtained dependences for the characteristic values of the $\mathrm{A}_{0}=1.3$ to 1.5 ,

$\mathrm{Z}=0.5\left(\mathrm{~A}_{0}+\mathrm{A}_{0}^{-1}\right)$,

$\mathrm{K}=2$ to 4 parameters showed that in this device, the change in the $\delta$ angle does not result in significant movement along the scales of $\varphi_{9}$ and $\varphi_{10}$ angles of sections of the gear ratio $\mathrm{j}$ maximum values; there is no significant change in the $\theta$ injection angle. When the new drive is running, the $\delta$ value of camshaft relative shift determines the form of the law of variation ratio of gear $\mathrm{j}\left(\varphi_{10}\right)$. If $\delta=0$, then the identity $\mathrm{j}\left(\varphi_{10}\right) \equiv 1$ operates, and the fuel pump shaft rotates evenly. As the $\delta$ value increases from zero to the limiting value $180^{\circ} /(2 \mathrm{~K})$, the degree of unevenness increases monotonically, and the maximum $\mathrm{j}_{\max }$ value of gear ratio $\mathrm{j}$ varies in accordance with the formula

$j_{\max }=1+R_{0}^{2}+2 R_{0}\left(1+R_{0}^{2}\right)^{0.5}$.

The graph of this function, as well as the forms of the resulting laws of changing $\mathrm{j}\left(\varphi_{10}\right)$ gear ratio $\mathrm{j}$, are shown in Figure 6 .

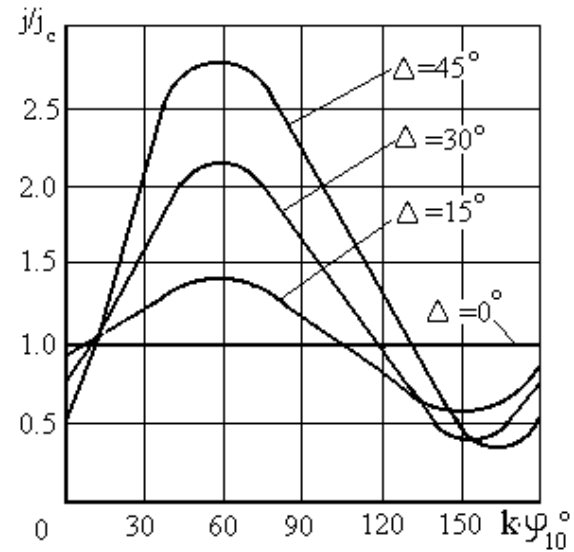

Fig. 6: Kinematic characteristics of the cam-and-lever link. 
Since the dependences of $\mathrm{R}_{0}$ и $\theta_{0}$ on $\delta$ for $К \delta \geq \pi / 4$ become essentially nonlinear, it is recommended to reduce the adjustment angle interval $\delta$ by two.

The value $\Delta$ of the cam plate one-side shift does not affect the degree of pump shaft rotation unevenness and the form of $\mathrm{j}\left(\varphi_{9}\right)$, $\mathrm{j}\left(\varphi_{10}\right)$ of the gear ratio change laws. Varying of this value results in to a consistent change in the phases of the $\mathrm{j}\left(\varphi_{9}\right)$ and $\mathrm{j}\left(\varphi_{10}\right)$ functions which is used in this device to obtain the required dependence of the $\theta$ injection advance angle and the $\mathrm{n}_{\mathrm{d}}$ diesel shaft rotation frequency. When determining the adjusting angle $\delta$ value, one can use the approximate formula

$\theta_{H}-\theta=\theta_{0}-0.5\left(j_{\max }-1\right) \cdot \Delta$

where $\theta_{\mathrm{H}}$ is advance angle in the nominal mode, and the $\theta_{0}$ and $\mathrm{j}_{\max }$ values are given by the dependences (6), (10).

Lever-eccentric adjustable drive of two-cylinder diesel engine fuel pump.

The analysis of the characteristics of the problem being solved for a two-cylinder diesel engine made it possible to simplify and improve the cam-and-lever transducer scheme. If the internal profile of the cam plate is described by a constant radius circle, then for the transfer function between the angles $\varphi_{1,2}$ of the first and second cranks rotation, we could obtain the following formula

$$
\varphi_{2}=\operatorname{arctg}\left(\frac{\mathrm{R}^{2}-\mathrm{e}^{2}}{\mathrm{R}^{2}+\mathrm{e}^{2}} \cdot \operatorname{tg} \varphi_{1}\right)+\arccos \frac{\mathrm{r}^{2}-\mathrm{L}^{2}}{\sqrt{\mathrm{R}^{4}+\mathrm{e}^{4}+2 \mathrm{e}^{2} \mathrm{R}^{2} \cos 2 \varphi_{1}}}
$$

where $\mathrm{R}$ is the crank length; $\mathrm{r}$ is the center profile radius; $\mathrm{e}$ is the eccentric eccentricity; $\mathrm{L}$ is the connector rod length. The compatibility condition for two parallel (convex and non-convex) chains has the form

$\mathrm{R}^{2}+\mathrm{e}^{2}=\mathrm{r}^{2}+\mathrm{L}^{2}$

If only the first summand is left on the right-hand side of formula (12) (that is, the mechanism with the joints correlation $r=L$ ), then the transfer function takes the form

$\varphi_{2}=\frac{\pi}{2}+\operatorname{arctg}\left(\frac{\mathrm{R}^{2}-\mathrm{e}^{2}}{\mathrm{R}^{2}+\mathrm{e}^{2}} \cdot \operatorname{tg} \varphi_{1}\right)$

Formula (14) coincides with the analogous transfer function of Hooke's joints. The average distance between the cranks will be $90^{\circ}$. Thus, a cam-and-lever link with an eccentric profile, under the condition $\mathrm{L}=\mathrm{r}$, is a kinematic analog of Hooke's joint. Let, as it was before, $j_{p}$ is the maximum degree of unevenness created in one transducer of angular velocities of the specified construction. Then the dimensions of the articulated chain joints can be determined from the following system of correlations

$$
\begin{aligned}
& \mathrm{L}^{2}=\mathrm{r}^{2}=\left[\frac{\mathrm{j}_{\mathrm{p}}}{\mathrm{j}_{\mathrm{p}}+1}\right] \cdot \mathrm{R}^{2} \\
& \mathrm{e}^{2}=\frac{\mathrm{j}_{\mathrm{p}}-1}{\mathrm{j}_{\mathrm{p}}+1} \cdot \mathrm{R}^{2}
\end{aligned}
$$

With the characteristic value $j_{p}=1.4$, these correlations have the following form

$$
L=r=0.75 R \text {, }
$$

and eccentricity is $e=0.4 R$.

Additional simplifications of the mechanism are associated with a change in the scheme of the higher pair closure. It is known that an eccentric cam can be replaced by a lever of radius $r$ fixed in its center. In this case, the second articulated chain for mechanism kinematic closure was unnecessary. The kinematic scheme obtained with this mechanism is shown in Fig. 7. In this scheme design, the lever was replaced by rolling 1 bearing inner race, located eccentrically to the mechanism axis. This scheme solves the problem successfully.

The simplicity of the technical solution described above makes it possible to recommend it for multi-cylinder diesel engines. In this case, before and after this mechanism, the up-and-down gears are installed.

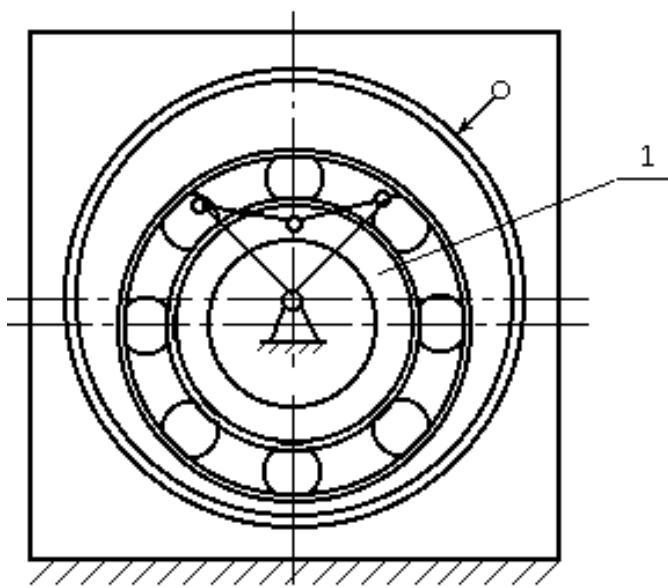

Fig. 7: Kinematic diagram of the lever-eccentric mechanism.

Let us dwell on some features of the kinematic and strength analysis of this mechanism. The diagram of the forces that load the joints of one of the stages is shown in Fig. 8.

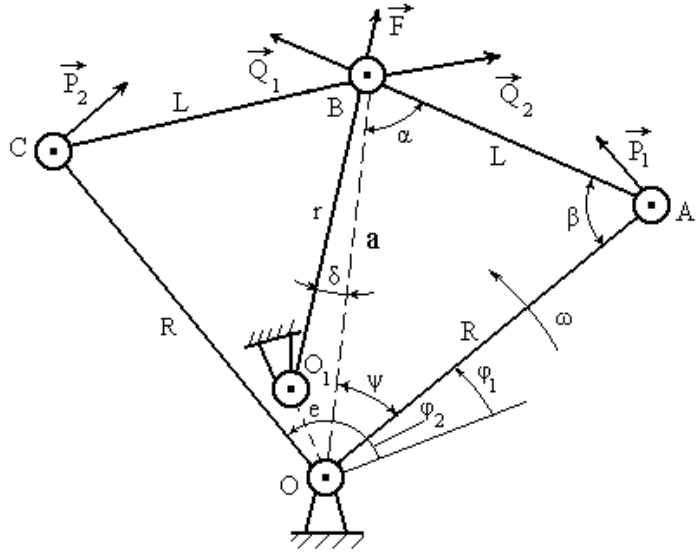

Fig. 8: The scheme of joints loading in the lever-eccentric mechanism.

We denote

$a=\sqrt{\left(1+j_{p}^{-1}\right)}$

Then the angles $\alpha, \beta, \delta, \psi, \varphi_{1}, \varphi_{2}$ are connected by the following system of correlation

$\sin \alpha=\mathrm{a} \cdot \sin \psi ;$

$\cos \delta=\mathrm{a} \cdot \cos \Psi$

$\beta=180^{\circ}-(\alpha+\psi)$;

$\varphi_{2}-\varphi_{1}=2 \psi=45^{\circ}+\operatorname{arctg}\left(\mathrm{j}_{\mathrm{p}}^{-1} \cdot \operatorname{tg} \varphi_{1}\right)-\varphi_{1}$

The instantaneous gear ratio $\mathrm{j}$ between the angular velocities of the $\mathrm{OA}$ and $\mathrm{OC}$ cranks can be obtained by equality differentiating (20), also $\mathrm{j}$ can be found as a function of the force transfer angles $\alpha$ and $\delta$

$\mathrm{J}=\sin (\alpha+\delta) / \sin (\alpha-\delta)$ 
Taking into account the above scheme and the analytical correlation, the driving forces and reactions in the joints within calculations are connected by the following dependences

$$
\begin{aligned}
& \left|\overrightarrow{\mathrm{Q}}_{1}\right|=\left|\overrightarrow{\mathrm{P}}_{1}\right| / \sin \beta \\
& \left|\overrightarrow{\mathrm{Q}}_{2}\right|=\left|\overrightarrow{\mathrm{P}}_{2}\right| / \sin \beta \\
& \left|\overrightarrow{\mathrm{P}}_{2}\right|=\left|\overrightarrow{\mathrm{P}}_{1}\right| / \mathrm{j} \\
& |\overrightarrow{\mathrm{F}}|=\mathrm{f} \cdot\left|\overrightarrow{\mathrm{P}}_{1}\right|
\end{aligned}
$$

Where

$$
f=\frac{\sin 2 \alpha}{\sin (\alpha+\psi) \cdot \sin (\alpha+\delta)}
$$

The peculiarity of using this mechanism is that at the diesel engine nominal operating mode, where the torque transmitted to the camshaft of the fuel pump is maximal, the total gear ratio (in two stages) is equal to 1 . The corresponding elements of the articulated chains move synchronously and form the same angles between each other at the same time, i.e. $\alpha_{1}=\alpha_{2} ; \beta_{1}=\beta_{2} ; \delta_{1}=\delta_{2}$. At the moments of plunger active progress, the angle $\varphi_{1}$ of the first stage driving crank rotation (and, correspondingly, the second stage driven crank) satisfies the equality $\varphi_{1} \approx 45^{\circ}$.

Taking this equation into account, all the angle values required can be obtained successively from the above formulas $\psi=$ $22,5^{\circ}+\operatorname{arctg}\left(1 / \mathrm{j}_{\mathrm{p}}\right) ; \mathrm{i}=2 \mathrm{j}_{\mathrm{p}} /\left(\mathrm{j}_{\mathrm{p}}{ }^{2}+1\right)$ and so on. The analysis of the results obtained in this case showed that in the range of $j_{p}$ values $\mathrm{j}_{\mathrm{p}}=1.3$ to 1.6 , which is common for devices of this assignment, the maximum values of the driving forces and reactions are related by the following approximate equalities

$$
\begin{aligned}
& \left|\overrightarrow{\mathrm{Q}}_{1 . \mathrm{M}}\right| \approx\left|\overrightarrow{\mathrm{Q}}_{2 . \mathrm{M}}\right| \approx\left|\overrightarrow{\mathrm{P}}_{1 . \mathrm{M}}\right| \\
& \left|\overrightarrow{\mathrm{F}}_{\mathrm{M}}\right| \approx 0,6 \ldots 0,8\left|\overrightarrow{\mathrm{P}}_{1 . \mathrm{M}}\right|
\end{aligned}
$$

where the value $\left|\overrightarrow{\mathrm{P}}_{1 . \mathrm{M}}\right|$ is proportional to the transmitted torque $\mathrm{M}_{\mathrm{\kappa p}}$

$\left|\overrightarrow{\mathrm{P}}_{1 . \mathrm{M}}\right|=\mathrm{M}_{\text {кр }} / \mathrm{OA} \mid$

The correlation above provides the basis for shafts strength calculation, junctions, joints at the design stage, which is expedient to produce using the method $[13,14]$.

\section{Conclusion}

We have proposed a new type of driven power mechanism for a diesel high-pressure fuel pump using a double cam-and-lever or lever-eccentric mechanism, which is more advanced than the known analogs. An algorithm for the kinematic calculation and a method for selecting the parameters of these mechanisms kinematic scheme have been developed based on the specified technical requirements. The optimal scheme for higher pair closure in the cam-and-lever transducer of uneven rotation has been chosen. The kinematic schemes have been developed and the parameter values corresponding to the formulated technical requirements have been found, the kinematic calculation and the foundations of mechanism strength computation have been presented.

\section{References}

[1] Patrakhaltsev NN, Strashnov SV, Melnik IS, Kornev BA, "Izmenenie chisla rabotayushchikh tsilindrov dizelya - variant povysheniya ekonomichnosti ego rezhimov malykh nagruzok", Avtomobilnaya promyshlennost, No. 2, (2012) pp.11-13, (in Russian).

[2] Napkhonenko NV, Karaeva MR, "Mnogofaktornaya optimizatsiya sistyemy gorodskikh passazhirskikh pyeryevozok s ispolzovaniyem gyenyetichyeskogo algoritma", Bulletin of the South-Russian State Technical University (NPI), No. 4, (2011), pp. 64-69, (in Russian).

[3] Napkhonenko NV, Karaeva MR, "Optimizatsiya sistyemy passazhirskikh pyeryevozok s uchyetom dinamichno myenyayushchikhsya passazhiropotokov", Bulletin of the SouthRussian State Technical University (NPI), No. 4, (2013) pp. 109 112, (in Russian).

[4] Moroz MM, Korol SO, Boiko YO, "Social traffic monitoring in the city of Kremenchuk", Actual Problems of Economics, No. 1 (175), (2016), pp. 385-398.

[5] Patrakhaltsev NN, Neustanovivshiesya rezhimy raboty dvigateley vnutrennego sgoraniya, Moscow: RUDN, (2009), (in Russian)

[6] Gorbunov PV, Efros VV, "Uluchshenie toplivopodachi na chastichnykh rezhimakh dizeley vnedorozhnoy tekhniki", Traktory $i$ selskokhozyaystvennye mashiny, No. 5, (2007), pp. 30-32, (in Russian).

[7] Efros VV, Gorbunov PV, "Puti sovershenstvovaniya toplivopodachi $\mathrm{v}$ dizelyakh vnedorozhnoy tekhniki", Traktory $i$ selskokhozyaystvennye mashiny, No. 4, (2007), pp. 31-34, (in Russian).

[8] Korol SO, Moroz MM, Korol SS, Serhiienko SA, "Method and device for increase of weight charging of four-stroke engine cylinders", Scientific Bulletin of National Mining University, No. 5 (161), (2017) pp: 56-61.

[9] Abramchuk FI, Vrublevskiy AN, Denisov AV, "Povyshenie ekologo-ekonomicheskikh pokazateley avtomobilnogo dizelya putem modifikatsii protsessa vpryskivaniya topliva", Avtomobilnyy transport, Vol. 16, (2005) pp. 303-305, (in Russian).

[10] Gritsyuk A. V. "Novye vozmozhnosti razdelennoy toplivnoy sistemy neposredstvennogo deystviya dlya uluchsheniya pokazateley malolitrazhnogo dizelya", Dvigateli vnutrennego sgoraniya, No. 2, (2009), pp. 32-35, (in Russian).

[11] Vrublevskiy AN, Denisov AV, Grigorev AL, "Otsenka vozmozhnosti stupenchatogo vpryskivaniya topliva $\mathrm{v}$ tsilindr dizelya 4DTNA s pomoshchyu dvukhpruzhinnoy forsunki", Dvigateli vnutrennego sgoraniya, No. 2, (2006), pp. 97-101, (in Russian).

[12] Patrakhaltsev NN, Kazakov SA, Fernando Kumara PID, "Pokazateli kachestva protekaniya neustanovivshikhsya rezhimov razgonov dizelya posle puskov", Avtomobilnaya promyshlennost, No. 3, (2011), pp. 35-38. (in Russian).

[13] Kukhar VV, Vasylevskyi OV, "Experimental research of distribution of strains and stresses in work-piece at different modes of stretch-forging with rotation in combined dies", Metallurgical and Mining Industry, No. 3, (2014) pp: 71-78.

[14] Kukhar V, Artiukh V, Butyrin A, Prysiazhnyi A, "Stress-Strain State and Plasticity Reserve Depletion on the Lateral Surface of Workpiece at Various Contact Conditions during Upsetting”, Advances in Intelligent Systems and Computing, Vol. 692, (2018) pp: 201-211. 